\title{
Evaluation of coefficients for an energy security indicators system
}

\author{
J. Augutis, R. Krikštolaitis, A. E. Lutynska, S. Pečiulytė \\ \& I. Žutautaitè \\ Vytautas Magnus University, Lithuania
}

\begin{abstract}
A sufficient security level of energy supply is vital to the functioning of modern economy since reliable supply is necessary to ensure industrial activities and satisfy population needs. In our previous papers (Lithuanian energy security level assessment based on indicator dependence (2011), Dynamic model for energy security level assessment (2012)) there was constructed a system of energy security indicators for the investigation of the Lithuanian energy security level. A security indicator is a special index which provides numerical values to important issues for the security of energy sector. Further, a dynamic indicator model, which includes interdependencies between indicators, was created for assessment of the energy security level. This model enables us to forecast the Lithuanian energy security level according to different development scenarios, such as a building of liquefied natural gas (LNG) terminal, electricity connection between Sweden and Lithuania (NordBalt), etc. Since technical parameters of new objects are not exactly known; their influence on indicators are expressed as random variables with known probabilistic distributions. A security indicators model based on historic data is adjusted by a probabilistic model of LNG or NordBalt influence on indicators using the Bayesian approach. The purpose of this paper is to evaluate the coefficients in a dynamic model of indicators for energy security level assessment. These coefficients are calculated in two ways: using algebraic and least square methods. This paper presents the dynamic indicator model, calculation methods of coefficients of indicators equations system and pilot calculations.
\end{abstract}

Keywords: energy supply security, differential equations, Bayesian approach. 


\section{Introduction}

In recent years issues on energy security have been extensively discussed in the literature. At the same time there is no single definition of energy security. A commonly cited definition of energy security contains four major elements, i.e. availability, accessibility, affordability and acceptability [3, 4]. This concept is widely used and encompasses the majority of definitions. Also definition of energy security was proposed by some international organizations. The International Energy Agency (IEA) [5] defines energy security as "a reliable possibility to obtain a required amount of energy in reasonable prices", whereas World Energy Council (WEC) describes it as the protection of citizens, society, economy and state from threats to reliable fuel and energy supply [6].

Relevance of energy security issue of Lithuania might be mentioned in several aspects. First of all, Lithuania as well as other Baltic States is still an energy island within the European energy infrastructure, lacking gas and electricity interconnections with the rest of EU, being dependent on external energy supply: few countries supply primary energy sources, there are no networks of gas, oil and electricity to Western Europe and the transmission grid needs modernization. The comparison of appropriate primary energy sources between Lithuania and EU-27 in 2010 is presented in Fig. 1.

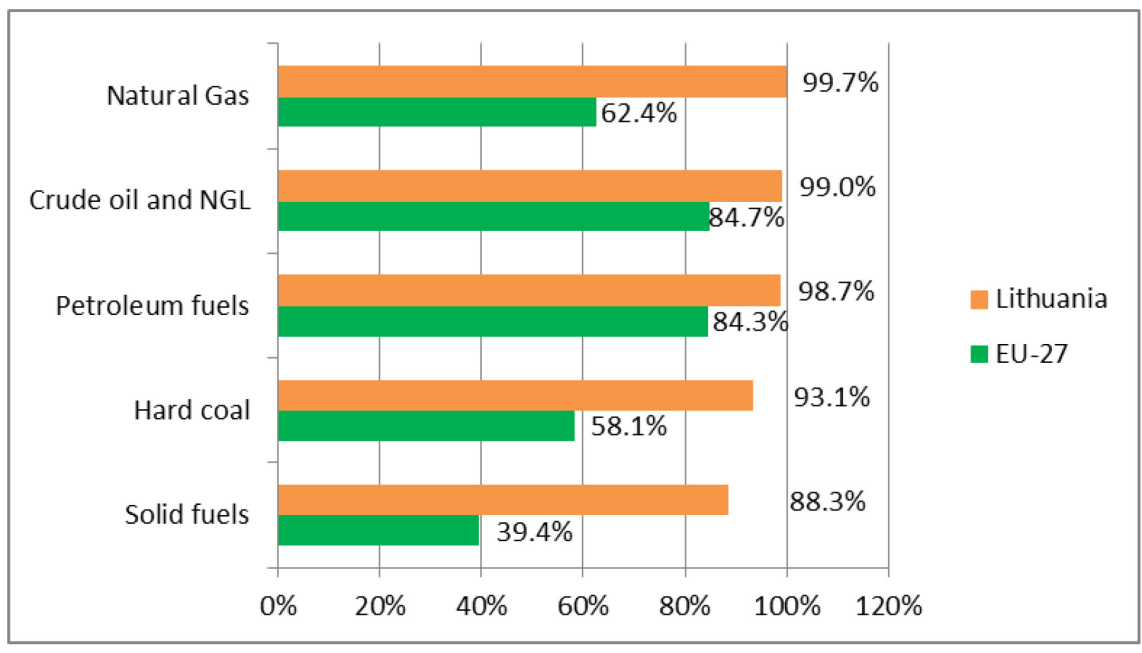

Figure 1: $\quad$ Import dependency in 2010 [8].

Second, due to the accession of the Republic of Lithuania to the EU, Lithuania committed to shutdown the first Ignalina NPP block in 2004 and the second block in 2009 [7]. Consequently, from 2010 Lithuania became electricity importer country instead of electricity exporter. As a result, electricity and gas prices, import dependency of energy related sources were increased. However, it is necessary to mention some positive tendencies, such as, decreasing of market 
share of the largest generator in the electricity market increasing use of renewable resources in the electricity market.

For assessing security of energy supply different approaches could be used: economical modeling, probabilistic modeling, geopolitical assessment of scenarios, expert risk assessment, analysis of primary energy sources, etc. But the most widely used and found in literature are the methods based on the analysis of indicators or indexes $[4,9,10]$. The analysis is mostly restricted by a list of indicators with its metrics which describes the energy situation in a particular country or region.

A security indicator is a special index which provides numerical values to important issues for the security of energy sector. The values of security indicators are mostly obtained from statistical data. These values of indicators are usually obtained in the particular time moments, however, indicators change continuously. So, it is advisable to construct a dynamic model of indicators, which includes interdependencies between these indicators. The two types of dynamic models were briefly investigated in [11].

The dynamic model of indicators will enable us to forecast the Lithuanian energy security level according different energy system development scenarios, such as building of liquefied natural gas (LNG) terminal, power interconnections between Lithuania and Sweden (NordBalt), etc. In this case we should correct the initial conditions of differential equations system. Since technical parameters of new objects are not exactly known, these uncertainties should be reflected in the initial conditions. Thus, in such conditions, the values of indicators are random variables. Their estimates are obtained in this paper using a modified application of Bayesian approach.

\section{Dynamic indicator model}

Let us construct a homogeneous differential equations system, according to the interdependencies between indicators

$$
\left\{\begin{array}{l}
\frac{\mathrm{d} I_{1}(\mathrm{t})}{\mathrm{d} t}=a_{11} I_{1}(t)+a_{12} I_{2}(t)+\cdots+a_{1 N} I_{N}(t), \\
\frac{\mathrm{d} I_{N}(\mathrm{t})}{\mathrm{d} t}=a_{N 1} I_{1}(t)+a_{N 2} I_{2}(t)+\cdots+a_{N N} I_{N}(t),
\end{array}\right.
$$

here $a_{i j}, i, j=1, \ldots, N$ are coefficients, $I_{i}, i=1, \ldots, N$ - energy security indicators.

Let us use the following definitions

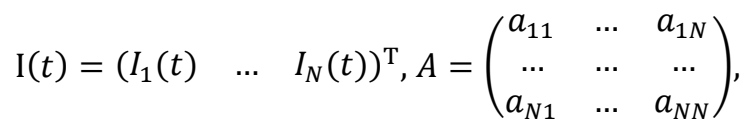

then (1) differential equations system we can write in the matrix form 
104 Safety and Security Engineering V

$$
\frac{\mathrm{dI}(t)}{\mathrm{d} t}=\mathrm{A} \mathrm{I}(t)
$$

The expression of the solution of differential equations system (2) depends on eigenvalues $\lambda$ of matrix A. If all eigenvalues are real and different numbers, the solution may be found according to the formula (3)

$$
\mathrm{I}(t)=\sum_{j=1}^{N} C_{j} B_{j} e^{\lambda_{j} t}
$$

and if eigenvalues are complex numbers $\lambda_{j}=\alpha_{j}+\beta_{j} \mathrm{i}, j=1,2, \ldots, N / 2,(N$ is even number in this case) the solution may be found according to the formula (4)

$$
\begin{aligned}
\mathrm{I}(t)=\sum_{j=1}^{N / 2}\left(\tilde{C}_{2 j-1} B_{2 j-1} e^{\alpha_{2 j-1} t}\left(\cos \beta_{2 j-1} t+\mathrm{i} \sin \beta_{2 j-1} t\right)\right. \\
\left.+\tilde{C}_{2 j} B_{2 j} e^{\alpha_{2 j-1} t}\left(\cos \beta_{2 j-1} t+\mathrm{i} \sin \beta_{2 j-1} t\right)\right)
\end{aligned}
$$

here $\mathrm{B}=\left(b_{1}, \ldots, b_{n}\right)^{\mathrm{T}}-$ vector of constants, $\tilde{C}_{j}=C_{j}+\mathrm{i} C_{j}$. Also the solution of differential equations system (2) may be the combination of expressions from formulae (3) and (4).

Let us give the variation for each indicator $\Delta I_{i}(t)=\left(I_{i}(t+\Delta t)-I_{i}(t)\right) / \Delta t$, $i=1, \ldots, N$ and construct system of algebraic equations

$$
\left\{\begin{array}{c}
\Delta I_{1}(t)=a_{11} I_{1}(t)+\cdots+a_{1 N} I_{N}(t) \\
\cdots \\
\Delta I_{N}(t)=a_{N 1} I_{1}(t)+\cdots+a_{N N} I_{N}(t)
\end{array}\right.
$$

here $a_{i j}, i, j=1, \ldots, N$ are unknown coefficients, $I_{i}(t), i=1, \ldots, N$ - energy security indicators. We take the values of each indicator in time moments $t_{k}, k=1, \ldots, n$ and define $I_{i k}=I_{i}\left(t_{k}\right), i=1, \ldots, N, k=1, \ldots, n$. So, we have $N$ algebraic systems of $N$ equations with $N^{2}$ unknowns

$$
\Delta I_{i k}=a_{i 1} I_{1 k}+a_{i 2} I_{2 k}+\cdots+a_{i N} I_{N k}, i=1, \ldots, N, k=1, \ldots, n .
$$

Coefficients $a_{i j}, i, j=1, \ldots, N$ in formula (1) (or (6)) may be calculated using different methods: algebraic, statistical, etc. In [2] we proposed to use algebraic method (AM) for calculation of these coefficients. In this method the matrix of coefficients is obtained in such way

$$
\mathrm{A}=\Delta \mathrm{I} \mathrm{I}^{-1},
$$

here $\Delta \mathrm{I}$ - is matrix of variations, $\mathrm{I}$ - matrix of indicators: 


$$
\Delta \mathrm{I}=\left(\begin{array}{ccc}
\Delta \mathrm{I}_{11} & \ldots & \Delta \mathrm{I}_{1 N} \\
\ldots & \ldots & \ldots \\
\Delta \mathrm{I}_{N 1} & \ldots & \Delta \mathrm{I}_{N N}
\end{array}\right), \quad \mathrm{I}=\left(\begin{array}{ccc}
I_{11} & \ldots & I_{1 N} \\
\ldots & \ldots & \ldots \\
I_{N 1} & \ldots & I_{N N}
\end{array}\right) .
$$

Algebraic method is quite limited, as we should have square matrices. So, the number of indicators and the number of time moments (when factual values of indicators are observed) must be the same, i.e. $n=N$.

In this paper we propose to use least square method (LSM) for coefficients calculation. LSM are applied to calculate estimates of unknowns coefficients of equations (6) with assumption that $a_{i i}=0, i=1, \ldots, N$. For the application of LSM number of observed factual values of indicators $n: n \geq N-1$. In this way, all collected statistical data about factual values of indicators may be used.

Aiming to find a particular solution for differential equations system (2), i.e. particular expression of each indicator as on time dependent function, we need to formulate initial conditions for differential equations system. Constants $C_{i}$, $i=1, \ldots, N$ of general solution may be found by solving system of differential equations (2) in time moment $t_{0}$

$$
I_{1}\left(t_{0}\right)=I_{1}^{0}, \ldots, I_{N}\left(t_{0}\right)=I_{N}^{0},
$$

here $I_{i}^{0}, i=1, \ldots, N$ - normalized factual value of indicator in year $t_{0}$.

Created dynamic indicators model will enable us to forecast the Lithuanian energy security level according to different factors, such as building liquefied natural gas terminal or other project. In this case we should correct the initial conditions (8) of differential equations system. Since technical parameters of new objects are not exactly known, these uncertainties should be reflected in the initial conditions. Thus, in such conditions, the values of indicators are random variables. In mathematical statistics theory it is well known that Bayesian approach (BA) allows a combination of two kinds of information: prior (for instance, generic statistic data, subjective option of experts) and measurements or observations [12]. BA allows updating estimates of all parameters in the model with a single new obtained observation, i.e. BA does not require to have new information on the values of all indicators involved in the created model.

In case of random initial conditions, $C_{i}, i=1, \ldots, N$, in (3) or (4) solution of differential equations system (2) are random variables as well, assumed as independent with prior probability density functions (pdfs) $p_{i}\left(x_{i}\right), i=1, \ldots, N$.

In this research work non-stationary processes are analysed, i.e. the values of indicators depends on time $t$. Classical application of BM is not correct in this case, because observations obtained in different time moments represent the other state of the indicators. The modified application of BA for the calculation estimates of parameters of non-stationary process mathematical models is presented in research paper [13]. 


\section{Calculating example}

For practical demonstration of proposed method three indicators are used for the analysis. The first one is technical indicator $\left(I_{1}(t)\right)$, which integrates technical parameters of energy system (electricity, gas, oil and heat). The main component of this indicator is installed power capacity of generators to maximal power demand in all mentioned sectors. Also this indicator joins energy system objects' lifetime, storage possibilities of resources, etc. The second indicator is an economic indicator $\left(I_{2}(t)\right)$, which integrates economic aspects of energy system functioning. This indicator is mostly related with market and prices in appropriate energy sectors, energy resources import, possibilities to choose suppliers, etc. And the last indicator is socio-political $\left(I_{3}(t)\right)$, which integrates geopolitical and socio-political aspects. It joins such things as political risk of resource supplier country and resource transit country, average expense for energy, degrees of undertaking the EU commitment, etc.

Statistical data of 2001-2010 was used for the verification of the proposed methods. Coefficients $a_{i j}, i, j=1, \ldots, 3$, of (1) differential equation system were calculated using: algebraic method and least square method.

The matrices of coefficients in each model

$$
\mathrm{A}_{A M}=\left(\begin{array}{ccc}
0.069 & -0.133 & 0.042 \\
-0.068 & 0.127 & -0.024 \\
0.388 & -0.730 & 0.458
\end{array}\right), \quad \mathrm{A}_{L S M}=\left(\begin{array}{ccc}
0 & -0.070 & 0.001 \\
0.004 & 0 & 0.117 \\
0.326 & -0.208 & 0
\end{array}\right)
$$

The matrices of coefficients are quite similar in both methods, i.e. $\| \mathrm{A}_{A M}-$ $\mathrm{A}_{L S M} \|=0.52$. The separate solution of differential equations system (2) was obtained using data of year 2010 in initial conditions (8). Further these dynamic models were used for forecasting values of indicators in years 2011 and 2012. The obtained values were compared with the factual values of indicators in these years (see Table 1).

Table 1: $\quad$ Comparison of indicator values.

\begin{tabular}{|c|c|c|c|c|c|c|}
\hline \multirow{3}{*}{ Indicator } & \multicolumn{2}{|c|}{ Factual } & \multicolumn{2}{|c|}{$\begin{array}{l}\text { Dynamic model } \\
\text { with matrix } A_{A M}\end{array}$} & \multicolumn{2}{|c|}{$\begin{array}{l}\text { Dynamic model } \\
\text { with matrix } A_{L S M}\end{array}$} \\
\hline & \multicolumn{6}{|c|}{ Year } \\
\hline & 2011 & 2012 & 2011 & 2012 & 2011 & 2012 \\
\hline Technical & 63.30 & 59.65 & 63.64 & 62.80 & 62.83 & 61.19 \\
\hline Economic & 68.53 & 70.73 & 68.87 & 69.93 & 70.17 & 72.54 \\
\hline Socio-political & 57.36 & 58.37 & 55.59 & 55.35 & 57.62 & 59.45 \\
\hline & \multicolumn{2}{|c|}{ Mean of error } & \multicolumn{2}{|c|}{1.57} & \multicolumn{2}{|c|}{1.14} \\
\hline
\end{tabular}


As we can notice, the indicator values obtained by dynamic model with coefficients matrix $\mathrm{A}_{L S M}$ are more accurate (see Table 1). Therefore the least square method will be chosen for further calculation of coefficients for differential equation system (2).

Using factual values of indicators in year 2001-2012 and LSM for the calculation of coefficients a differential equation system is constructed

$$
\left\{\begin{array}{l}
\frac{\mathrm{d} I_{1}(\mathrm{t})}{\mathrm{d} t}=-0.090 I_{2}(t)+0.047 I_{3}(t) \\
\frac{\mathrm{d} I_{2}(\mathrm{t})}{\mathrm{d} t}=0.063 I_{1}(t)-0.004 I_{3}(t) \\
\frac{\mathrm{d} I_{3}(\mathrm{t})}{\mathrm{d} t}=0.447 I_{1}(t)-0.357 I_{2}(t)
\end{array}\right.
$$

General solution of (9) differential equation is constructed as combination of expressions from formulae (3) and (4):

$$
\left\{\begin{array}{c}
I_{1}(t)=C_{1}(2.66 \cos (0.02 t)+3.63 \sin (0.02 t)) \mathrm{e}^{0.08 t} \\
+C_{2}(3.635 \cos (0.02 t)-2.66 \sin (0.02 t)) \mathrm{e}^{0.08 t}+0.89 C_{3} \mathrm{e}^{-0.15 t} \\
I_{2}(t)=C_{1}(1.14 \cos (0.02 t)+2.8 \sin (0.02 t)) \mathrm{e}^{0.08 t} \\
+C_{2}(2.8 \cos (0.02 t)-1.14 \sin (0.02 t)) \mathrm{e}^{0.08 t}-0.46 C_{3} \mathrm{e}^{-0.15 t} \\
I_{3}(t)=C_{1}(7.9 \cos (0.02 t)+10.18 \sin (0.02 t)) \mathrm{e}^{0.08 t} \\
+C_{2}(10.18 \cos (0.02 t)-7.9 \sin (0.02 t)) \mathrm{e}^{0.08 t}-3.74 C_{3} \mathrm{e}^{-0.15 t}
\end{array}\right.
$$

Constants $C_{i}, i=1,2,3$, of general solution are calculated using normalized factual values of indictors $I_{i}, i=1,2,3$ in 2010: $C_{1}=-41.44, C_{2}=43.95$, $C_{3}=17.25$.

Aiming at valuating Lithuanian energy security state after building LNG terminal in 2014 or electricity power link NordBalt in 2016, we need to correct values of obtained constants according to forecasted values of indicators. Information about LNG terminal or NordBalt start-up date, power and costs are inaccurate. In general case, values of indicators are unknown, i.e. assumed as random variables. Generalized information is used to forecast values of indicators and errors of estimates. Probable values $I_{i}{ }^{*}$ of indicators $I_{i}$ in cases of three different scenarios are presented in Table 2 . In this research paper three scenarios are analysed:

Scenario 1 - neither LNG terminal nor NordBalt are constructed,

Scenario 2 - LNG plant will start-up in 2014,

Scenario 3 - NordBalt will be operational in 2016.

Table 2: $\quad$ Probable values of indicators in cases of two different scenarios.

\begin{tabular}{l|c|c|c}
\hline Indicator & Technical & Economic & Socio-political \\
\cline { 1 - 1 } Scenario & 66.24 & 70.86 & 57.09 \\
Scenario 2 & 65.22 & 69.36 & 58.44 \\
\hline
\end{tabular}


Let us assume that at time moment $t$ probability distributions of indicators $I_{i}(t)$ are normal with means that satisfy equality $(10)$, here $C_{i}(i=1,2,3)$ are independent random variables. $C_{i}$ can be determined using sum of constants and indicators products (form system of equations (10)). In case of normal distributions of indicators, probability distributions of random variables $C_{i}$ $(i=1,2,3)$ are normal as well with means equal to values that are calculated for 2010 , i.e. general solution of system of equations (10). Denote means are $c_{1}=-41.44, c_{2}=43.95, c_{3}=17.25$ and standard deviations are $10 \%$ of its means, i.e. $s_{i}=0.1 c_{i}(i=1,2,3)$. BA was applied to update point estimates of random variables $C_{i}(i=1,2,3)$. Forecasted mean values of indicators calculated with BA point estimates of random variables $C_{i}(i=1,2,3)$ are presented in Table 3.

Table 3: $\quad$ Forecasted mean values of indicators in different scenarios.

\begin{tabular}{|c|c|c|c|c|c|c|c|}
\hline \multirow[t]{2}{*}{ Indicator } & \multirow[b]{2}{*}{ Years } & \multicolumn{2}{|c|}{ Technical } & \multicolumn{2}{|c|}{ Economic } & \multicolumn{2}{|c|}{ Socio-political } \\
\hline & & 2014 & 2016 & 2014 & 2016 & 2014 & 2016 \\
\hline Scenario 1 & & 59.58 & 56.98 & 72.77 & 75.05 & 58.91 & 58.67 \\
\hline Scenario 2 & & 65.47 & 65.20 & 71.15 & 73.68 & 57.29 & 59.17 \\
\hline Scenario 3 & & - & 64.08 & - & 69.94 & - & 58.70 \\
\hline
\end{tabular}

In Figs 2-4 are given functions of technical, economic and socio-political indicators in scenarios $1-3$.

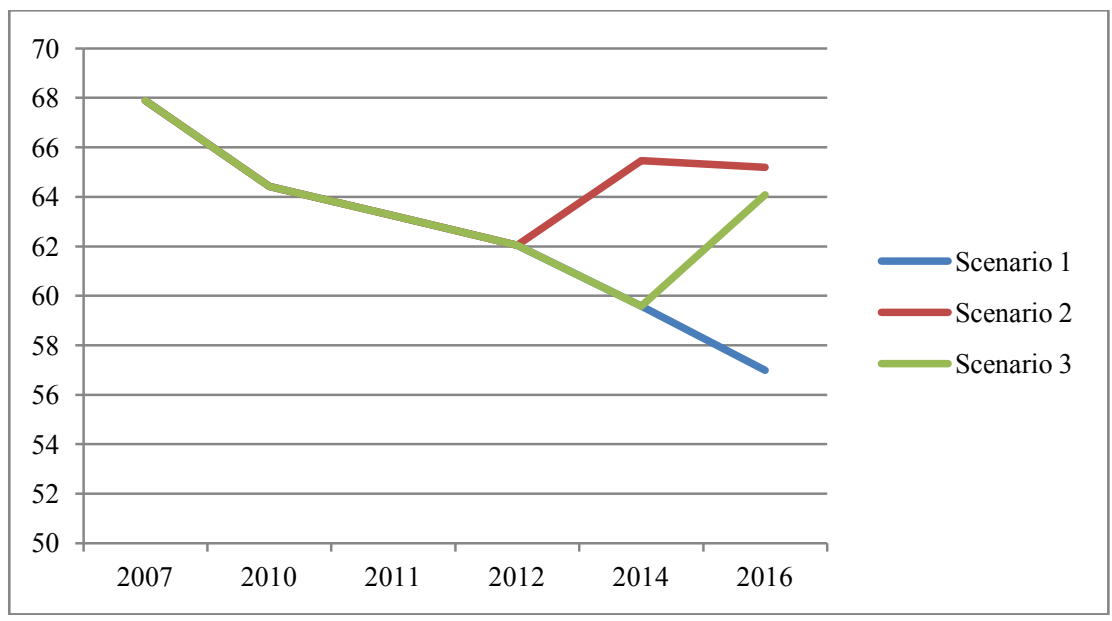

Figure 2: $\quad$ Graph of technical indicator $I_{1}(t)$.

As we can see from Figs 2-4, incorporation LNG terminal to energy system is giving the biggest positive influence for every indicator. 


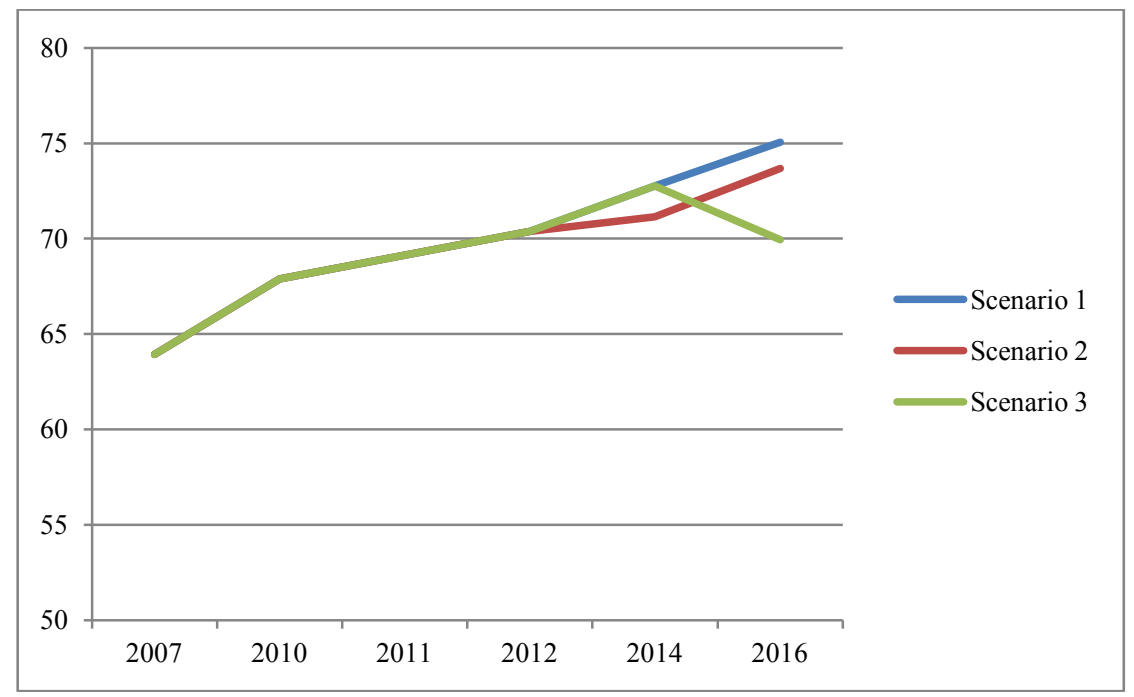

Figure 3: Graph of economic indicator $I_{2}(t)$.

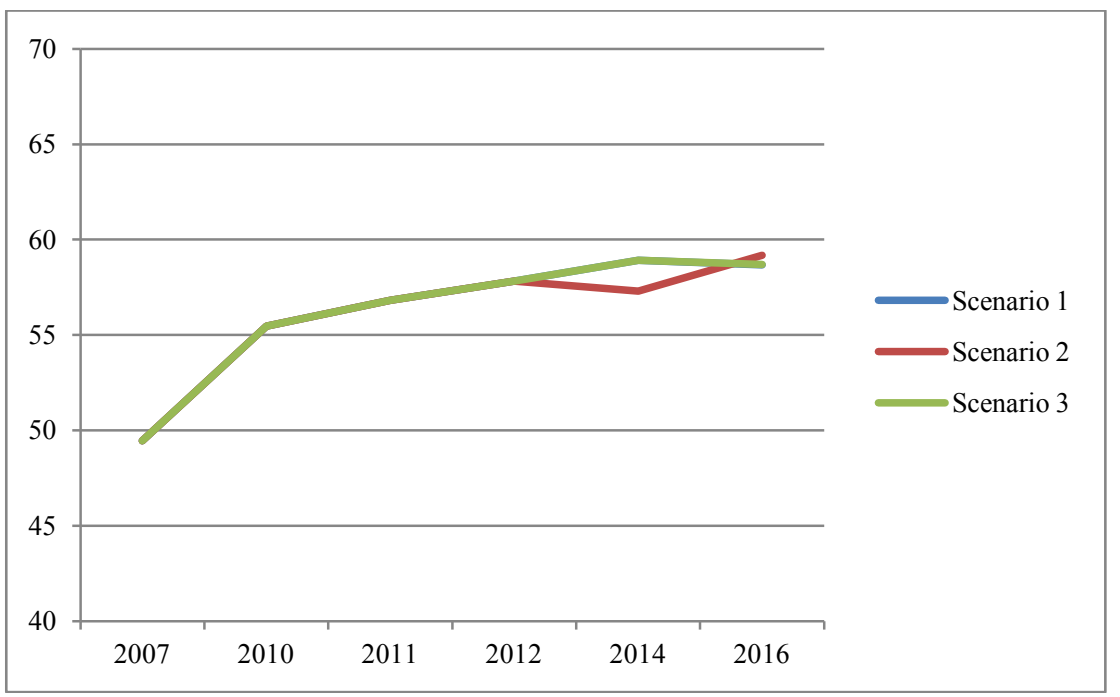

Figure 4: $\quad$ Graph of socio-political indicator $I_{3}(t)$ (Scenarios 1 and 3 coincide in this case).

In order to identify the energy security state of the system, a 100 percent system assessment scale is used. The scale is divided into three main parts: normal state (66.67-100 percent), pre-critical state (33.33-66.67 percent) and critical state ( $0-33.33$ percent). These three parts are further subdivided into five equal parts accordingly. The value of each indicator is evaluated by percent during the research year. The state of energy supply security is evaluated taking 
into account the weights of indicators (we used equal weights of indicators) and the evaluation of indicators according to the following formula

$$
B=s_{1} I_{1}^{p}+s_{2} I_{2}^{p}+s_{3} I_{3}^{p}
$$

here $I_{i}^{p}, i=1,2,3$ - value of indicator in percent, $s_{i}, i=1,2,3$ - weight of each indicator. Integral characteristics of Lithuanian energy supply security is presented in Table 4 and Fig. 4 for scenarios 1-3.

Table 4: $\quad$ Lithuanian energy supply security state.

\begin{tabular}{lll}
\hline & \multicolumn{3}{c}{ Year } \\
Scenario & 2014 & 2016 \\
\hline Scenario 1 & 60.00 & 60.00 \\
Scenario 2 & 64.44 & 64.44 \\
Scenario 3 & 60.00 & 62.22 \\
\hline
\end{tabular}

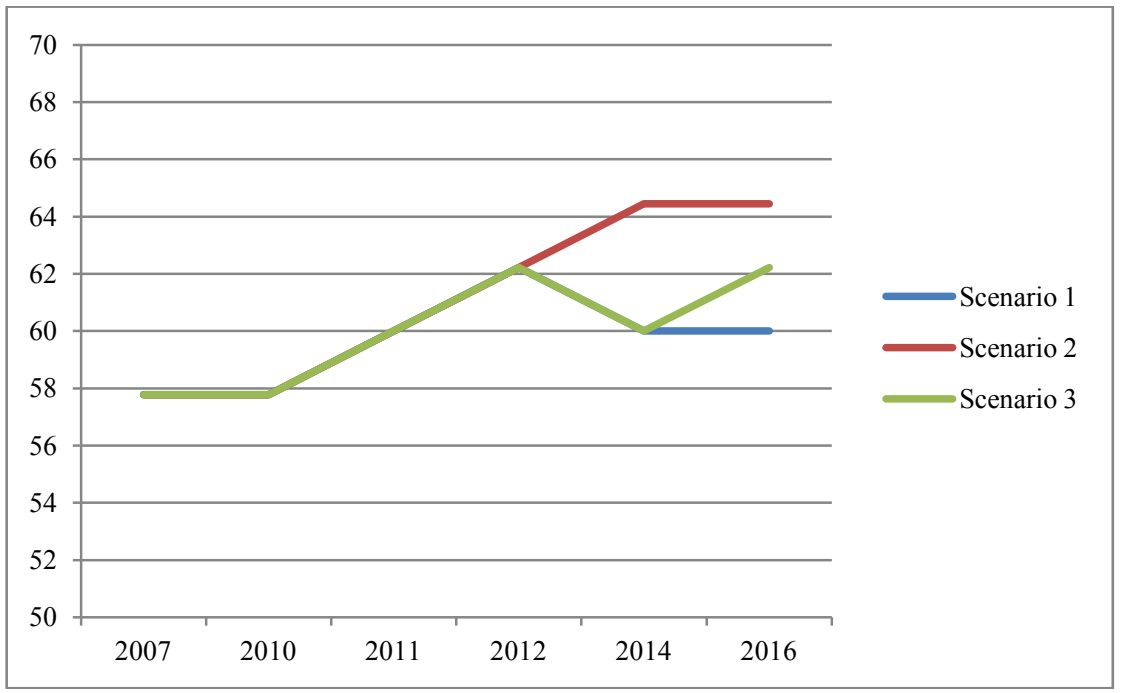

Figure 5: Lithuanian energy supply security state.

The results presented in Table 4 and Figure 5 show that the best choice for Lithuania is building LNG terminal in terms of energy security. This situation is normal, as new LNG terminal is energy security increasing object in all aspects, e.g. diversification of gas suppliers is positive factor for decreasing gas prices, which in Lithuania is currently the largest in Europe. Also the positive impact on energy security is giving power link NordBalt, which is a prerequisite for the common Baltic-Nordic electricity market. This power link will enable Lithuania to purchase electricity from Northern European countries that are rich in hydro energy resources. 


\section{Conclusions}

1. The method how to relate system of any indicators with differential equations system is proposed. The solution of this differential indicators system can be used for evaluation of indicators in the future.

2. The method, based on Bayesian approach, how to involve preliminary information with uncertainties on future energy projects into energy indicators evaluation system is proposed.

3. The created methodology enables us to compare integral characteristics of energy supply security for different scenarios. According to this methodology, the energy security level is the highest after building LNG terminal (64.44 percent in 100 percent scale). Electricity interconnection between Lithuania and Sweden raises integral energy security level till 62.22 percent. However, the aggregation of all positive and negative consequences leads to the conclusion that energy security level did not significantly change in all scenarios. In all cases the energy security level is seen as pre-critical. In pessimistic scenario, when no new energetics objects are built, Lithuanian energy supply security level decreases to 60.0 percent in 2016 .

\section{Acknowledgement}

This research was funded by a grant (No. ATE-06/2012) from the Research Council of Lithuania.

\section{References}

[1] Augutis J., Krikštolaitis R., Pečiulytė S. Lithuanian energy security level assessment based on indicator dependence. Fourth International Conference on Safety and Security Engineering. WitPress, 2011. Safe IV. ISBN 978-184564-522-9, p. 71-82.

[2] Augutis J., Pečiulytė S., Krikštolaitis R., Žutautaitė I., Ušpuras E. Dynamic model for energy security level assessment. Risk analysis VIII: Eighth International Conference on Simulation in Risk Analysis and Hazard Mitigation. WitPress, 2012. ISBN 978-1-84564-620-2, p. 21-30.

[3] Winzer Ch. Conceptualizing energy security, Energy Policy 2012; 46: 3648.

[4] Sovacool BK, Mukherjee I. Conceptualizing and measuring energy security: A synthesized approach, Energy 2011; 36: 5343-5355.

[5] International Energy Agency. http://www.iea.org/topics/energysecurity/

[6] World Energy Council. http://www.worldenergy.org/

[7] European Union. Access to European Union law. http://eur-lex.europa.eu/

[8] European Commission. Statistics and Market observatory. http://ec.europa.eu/energy/observatory/index_en.htm

[9] Augutis J, Krikštolaitis R, Martišauskas L, Pečiulytė S. Energy security level assessment technology, Appl Energy 2012; 97: 143-149. 
[10] Kruyt B, Van Vuuren DP, de Vries HJM, Groenenberg H. Indicators for energy security, Energy Policy 2009; 37: 2166-2181.

[11] Mixalevich, A.A., Bykova, E.V., Postolatii, V.M., Fisenko, S.P., Shnip, A.I., Rimko, D.V., Grodecki, M.V., Methodological approaches to solving the energy security problem in Moldova and Belarus. Kishinev, pp. 100, 2010 (in Russian).

[12] Bernardo, J. M., Smith, A. F. M., Bayesian theory. John Wiley and Sons, pp. 357-361, 2003.

[13] Augutis, J., Žutautaitė, I., Radziukynas, V., Krikštolaitis, R., Kadiša, S., Application of Bayesian method for electrical power system transient stability assessment. International journal of electrical power and energy systems, 42, pp. 465-472, 2012. 